\title{
Clinical and genetic basis of familial amyotrophic lateral sclerosis
}

\author{
Bases clínicas e genéticas da esclerose lateral amiotrófica familiar \\ Paulo Victor Sgobbi de Souza, Wladimir Bocca Vieira de Rezende Pinto, Marco Antônio Troccoli Chieia, Acary \\ Souza Bulle Oliveira
}

\begin{abstract}
Amyotrophic lateral sclerosis represents the most common neurodegenerative disease leading to upper and lower motor neuron compromise. Although the vast majority of cases are sporadic, substantial gain has been observed in the knowledge of the genetic forms of the disease, especially of familial forms. There is a direct correlation between the profile of the mutated genes in sporadic and familial forms, highlighting the main role of C9orf72 gene in the clinical forms associated with frontotemporal dementia spectrum. The different genes related to familial and sporadic forms represent an important advance on the pathophysiology of the disease and genetic therapeutic perspectives, such as antisense therapy. The objective of this review is to signal and summarize clinical and genetic data related to familial forms of amyotrophic lateral sclerosis.
\end{abstract}

Keywords: amyotrophic lateral sclerosis, motor neuron disease, neurogenetics, neurodegeneration, C9orf72 gene.

\section{RESUMO}

A esclerose lateral amiotrófica representa a forma mais comum de doença neurodegenerativa com comprometimento do neurônio motor superior e inferior. Embora a maioria dos casos seja esporádica, ganho impressionante referente ao conhecimento das formas genética da doença foi observado, em especial das formas familiares. Há uma correlação direta entre o perfil de genes mutados nas formas familiares e esporádicas, destacando-se o papel principal do gene C9orf72 nas formas clínicas associadas com espectro da demência frontotemporal. Os diferentes genes relacionados às formas familiares e esporádicas representam um importante avanço na fisiopatologia da doença e perespectivas terapêuticas genéticas, como a terapia antisense. 0 objetivo desta revisão é apontar e resumir os principais dados clínicos e genéticos relacionados às formas familiares da esclerose lateral amiotrófica.

Palavras-chave: esclerose lateral amiotrófica, doença do neurônio motor, neurogenética, neurodegeneração, gene C9orf72.

Amyotrophic Lateral Sclerosis (ALS) or Lou Gehrig's disease is the main progressive adult-onset neurodegenerative motor neuron disease (MND), affecting primarily upper (UMN) and lower motor neurons (LMN) giving rise to its typical neurological manifestations. Overall prevalence of ALS is around two to seven cases per 100000 inhabitants ${ }^{1,2}$, and incidence around one to two new cases per 100000 inhabitants per year ${ }^{2,3,4}$.

ALS arises as a consequence of multiple pathophysiological mechanisms and cellular dysfunctions (Figure 1), including protein misfolding and aggregation, altered RNA processing (mainly disturbed mRNA splicing and signaling), defects in axonal transport, abnormal metabolism and accumulation of reactive oxygen species, mitochondrial dysfunctions, microglial neuroinflammatory mechanisms, direct glutamate excitotoxicity by astrocytes, abnormal modulatory effects from other glial cells, disturbances of autophagy, ubiquitine-proteosome system abnormalities and primary and secondary ion channel $\operatorname{defects}^{5,6,7,8}$. Environmental and toxic factors also represent major factors, including traumatic sports mechanisms and toxic causes (including the ALS-parkinsonism/dementia of Guam) ${ }^{9}$.

Typical electrodiagnostic and clinical signs arise from a complex network of neuropathological changes including upper motor neuron degeneration in the frontal lobe (mainly Betz giant cells in the motor cortex), corticospinal and corticobulbar tracts (in the spinal cord, internal capsule and cerebral peduncles pathways), lower motor neurons in brainstem nuclei (motor nuclei of cranial nerves VII, $\mathrm{X}, \mathrm{XI}$ and XII) and in anterior horn motoneurons of the spinal cord. Onufrowicz-Mannen's nucleus and some cranial nerve motoneurons (motor nuclei of cranial nerves III, IV and VI) are generally spared, correlating with exceptionally 


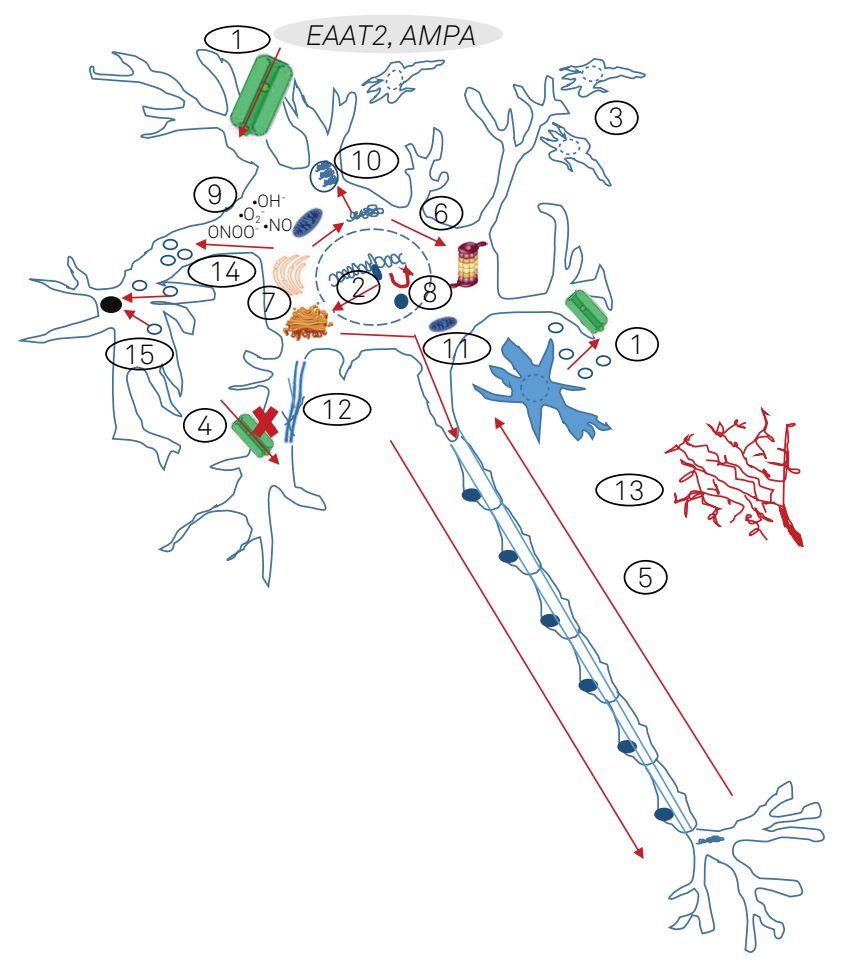

1. Direct glutamate astrocyte excitotoxicity (i.e. DAO, ALS2, HFE)

2. Altered RNA processing and metabolism (i.e. C9orf72, TARDBP, FUS, EWSR1, TAF15, ATXN2, HNRNPA1, SETX, ANG, SMN1, ELP3, MATR3)

3. Microglial neuroinflammatory activation (i.e. SOD1)

4. Secondary ion channel defects and transmembrane receptors (i.e.C9orf72, SIGMAR1, ERBB4, TRPM7, HFE)

5. Anterograde/retrograde axonal transport (i.e. SOD1, DCTN1, PRPH, SPG11, PRPH, CHMP2B, PFN1, KIFAP3)

6. Ubiquitin-proteosome system dysfunction (i.e. VCP, UBQLN2, SQSTM1, OPTN, FIG4)

7. Golgi-endosomal reticulum trafficking (i.e. OPTN, FIG4, SIGMAR1, VAPB, VCP)

8. Direct DNA lesion repair (i.e. SPG11, SETX, FUS, APEX1)

9. Abnormal accumulation of reactive oxygen species (i.e. SOD1, ALS2, APEX1, HFE, PON)

10. Toxic protein aggregates and misfolding (i.e. SOD1, VCP, UBQLN2, DAO, OPTN, SQSTM1)

11. Mitochondrial dysfunctions (i.e. CHCHD10, CYP27A1, COX1, IARS2)

12. Cytoskeleton dynamics and architecture (i.e. TUBA4A, PFN1, DCTN1, NEFH, PRPH)

13. Angiogenesis (i.e. ANG, VEGF)

14. Endosomal and vesicular trafficking (i.e. ALS2, VAPB, C9orf72, CHMP2B, OPTN, DCTN1, ATXN2, FIG4, VCP, UNC13A)

15. Disturbances of autophagy (i.e. FIG4, VCP, UBQLN2, SQSTM1)

Figure 1. Schematic representation of the main pathophysiological mechanisms involved in familial amyotrophic lateral sclerosis and the genetic changes involved in each case $e^{5,6,7,8}$.

rare compromises of facial and extrinsec ocular movements and sphincteral disturbances ${ }^{1,2}$. In microscopic evaluation, cytoplasmic Bunina bodies and Lewy body-like are motor neuron neuropathological hallmarks of ALS, although each genetic subtype commonly presents with their signatures. Neuropathological remarks include neurofilamentous swelling of proximal axons with reduced calibre of distal axons and axonal wallerian degeneration, accumulation of neurofilament and peripherin in axons and perikarium, reactive glyosis, Lewy body-like cytoplasmic neuronal inclusions, perikarial inclusions with phosphorylated neurofilament and ubiquitin immunoreactivity and positive immunoreactivity for other biochemical markers depending on genetic basis of the disease, mainly ubiquinated protein inclusions with positivity for TAR (Transactive response) DNA-binding protein 43 (TDP-43) ${ }^{2}$. Furthermore, different authors believe there is a regional spreading of intracellular misfolded pathogenic proteins SOD1 and TDP-43 involved in ALS in a prion-like propagation in an intercellular contiguous spreading fashion ${ }^{2,6,10}$.

Most cases of ALS present with asymmetric focal apendicular weakness progressing with bulbar dysfunction, quadriparesis and respiratory insufficiency leading to death in about two to three years after onset ${ }^{1}$. The combination of upper motor neuron and lower motor neuron signs of compromise is classically described with variable degrees of each component during disease progression ${ }^{1}$. Association with cognitive and behavioural disturbances is common and sometimes present with the classical phenotype of behavioral variant (bv) frontotemporal dementia (FTD). Although lability of affect commonly occurs, bvFTD, executive dysfunction and mood disorders occurs more frequently in some specific clinical and genetic conditions. A FTD clinical suspection can be properly analyzed applying specific criteria, including the Hodge's and Neary criteria ${ }^{11}$. Other cognitive compromise patterns also occurs including primary progressive nonfluent aphasia, logopenic progressive aphasia and semantic dementia. Around 5\% of sporadic and familial ALS cases fullfill properly diagnostic criteria for $\mathrm{FTD}^{11}$.

There are no specific clinical, neuroimaging and serum and cerebrospinal fluid biochemical markers to provide the definite diagnosis of ALS and clinicians must be aware about differential diagnosis and red-flags ${ }^{1}$. Clinical and electrodiagnostic findings are essential to guide the diagnosis process using both the revised El Escorial criteria and the Awaji-shima electrodiagnostic criteria. Although causative genes and susceptibility loci are well-established in sporadic and familial ALS (Table 1), presymptomatic testing does not represent a reliable and available diagnostic method in most neurological centers ${ }^{2,6}$.

Most cases of ALS are sporadic (90 to 95\% of ALS cases) and generally occurs in patients between the fifth and seventh decades of life. Familial ALS cases are defined when there is a context of more than one affected family member (relative) from first or second generation from the index or propositum case with the same disease presentation (despite the frequent occurence of intrafamilial clinical variability) and generally associates with: (i) earlier age at disease onset; (ii) more commonly symptom onset starts in the lower extremities; and (iii) longer or shorter disease duration, life expectancy and clinical progression, depending on particular genetic subtypes ${ }^{2,12,13}$. Familial cases can occur in an autosomal recessive or dominant or dominant X-linked inheritance patterns. Most adult-onset cases of familial ALS have autosomal dominant inheritance pattern, while juvenile-onset cases have autosomal recessive pattern, in a similar way to the observed with autosomal recessive cerebellar ataxias and autosomal dominant spinocerebellar ataxias. Overall penetrance is age and gene-dependent 
Table 1. Genetic causes of amyotrophic lateral sclerosis, year of description, pattern of inheritance and allelic conditions $2,8,12,59$.

\begin{tabular}{|c|c|c|}
\hline Gene involved (locus) - year of description & Inheritance & Allelic disorders \\
\hline SOD1 (Superoxide dismutase 1; 21q22.11) - 1993 & $\mathrm{AD} / \mathrm{AR}$ & ALS1 \\
\hline C9orf72 (Chromosome 9 Open Reading Frame 72; 9p21.2) - 2011 & $A D$ & $\begin{array}{l}\text { FTD-ALS type 1, FTD, ALS, HD-like, atypical parkinsonism } \\
\text { (PSP-like, CBD-like, MSA-like), CJD-like, AZD-like }\end{array}$ \\
\hline FUS (Fused in Sarcoma; 16p11.2) - 2009 & $A D / A R$ & ALS6, Hereditary essential tremor type 4 \\
\hline CHMP2B (Chromatin-modifying protein member 2B; 3p11.2) - 2006 & $A D$ & ALS17, Chromosome 3-linked FTD \\
\hline ALS2 (Alsin; 2q33.1) - 2001 & AR & $\begin{array}{c}\text { ALS2, Juvenile Primary Lateral Sclerosis, Infantile-onset } \\
\text { Ascending Spastic Paralysis }\end{array}$ \\
\hline UBQLN2 (Ubiquilin 2; Xp11.21) - 2011 & $X D$ & ALS15 \\
\hline PFN1 (Profilin 1; 17p13.2) - 2012 & $A D$ & ALS18 \\
\hline OPTN (Optineurin; 10p13) - 2009/2010 & $A R / A D$ & $\begin{array}{c}\text { ALS12, primary open angle glaucoma type 1, Paget } \\
\text { disease of bone }\end{array}$ \\
\hline TARDBP (TAR DNA-binding protein; 1p36.22) - 2008 & $A D$ & ALS10, FTD \\
\hline SQSTM1 (Sequestosome 1; 5q35.3) - 2011 & $A D$ & ALS, Paget disease of bone \\
\hline PRPH (Peripherin; 12q13.12) - 2004 & $A D ?$ & ALS \\
\hline $\begin{array}{l}\text { HNRNPA1 (Heterogeneous Nuclear Ribonucleoprotein A1; } \\
\text { 12q13.13) - } 2013\end{array}$ & $A D$ & $\begin{array}{l}\text { ALS20, IBM with early-onset Paget disease without } \\
\text { FTD type } 3\end{array}$ \\
\hline DCTN1 (Dynactin 1; 2p13.1) - 2003 & $A D$ & $\begin{array}{l}\text { ALS, Perry syndrome, Distal hereditary motor } \\
\text { neuronopathy with vocal paresis (type VIIB) }\end{array}$ \\
\hline ANG (Angiogenin; 14q11.2) - 2006 & $A D$ & ALS9 \\
\hline $\begin{array}{l}\text { FIG4 (FIG4, S. cerevisiae, homolog of SAC1 lipid phosphatase } \\
\text { domain containing; 6q21) - } 2009\end{array}$ & $A D$ & $\begin{array}{c}\text { ALS11, Charcot-Marie-Tooth disease type 4J, Yunis-Varon } \\
\text { syndrome, Bilateral Temporooccipital Polymicrogyria, } \\
\text { Primary Lateral Sclerosis }\end{array}$ \\
\hline NEFH (Neurofilament protein, Heavy Polypeptide; 22q12.2) - 1999 & $A D$ & ALS \\
\hline VCP(Valosin-containing Protein; 9p13.3) - 2010 & $A D$ & ALS14, IBM with early-onset Paget disease and FTD type 1 \\
\hline SETX (Senataxin; 9q34.13) - 2004 & $A D$ & ALS4, ataxia with oculomotor apraxia type 2 (AOA2) \\
\hline $\begin{array}{l}\text { ERBB4 (V-Erb-B2 avian erythroblastic leucemia viral oncogene } \\
\text { homolog 4;2q34) - } 2013\end{array}$ & $A D$ & ALS19, schizophrenia, melanoma \\
\hline SIGMAR1 (Sigma Nonopioid Intracellular Receptor 1; 9p13.3) - 2011 & AR & ALS16 \\
\hline $\begin{array}{l}\text { VAPB (Vesicle-associated Membrane Protein-associated Protein } \\
\text { B;20q13.32) - } 2004\end{array}$ & $A D$ & ALS8, late-onset Spinal Muscular Atrophy Finkel type \\
\hline MATR3 (Matrin-3; 5q31.2) - 2014 & $A D$ & ALS21 \\
\hline $\begin{array}{l}\text { CHCHD10 (Coiled-coil-helix-coiled-coil-helix-domain-containing } \\
\text { protein 10;22q11.23) - } 2014\end{array}$ & $A D$ & FTD-ALS type 2 \\
\hline DAO (D-amino acid oxidase; 12q24) - 2010 & $A D$ & ALS, Schizophrenia \\
\hline ATXN2 (ataxin 2; 12q24.12) - 2010 & $A D$ & ALS13, Spinocerebellar ataxia type 2 \\
\hline SMN1 (Survival of Motor Neuron 1; 5q13.2) - 2012 & $A D$ & ALS, Spinal muscular atrophy (types 1-4) \\
\hline EWSR1 (Ewing sarcoma breakpoint region 1; 22q12.2) - 2012 & $A D$ & ALS, Ewing sarcoma, Neuroepithelioma \\
\hline $\begin{array}{l}\text { TAF15 (TAF15 RNA polymerase II, TATA box-binding protein- } \\
\text { associated factor, 68-kD; 17q12) - } 2011\end{array}$ & $A D$ & ALS, Extraskeletal myxoid chondrosarcoma \\
\hline SPG11 (SPG11 gene/spatacsin; 15q21.1) - 2010 & $A R$ & ALS5, Hereditary Spastic Paraplegia type 11 (SPG11) \\
\hline TUBA4A (Tubulin, alpha-4A; 2q35) - 2014 & $A D$ & ALS \\
\hline $\begin{array}{l}\text { TRPM7 (Transient Receptor Potential Cation Channel, Subfamily } \\
\text { M, Member 7; 15q21.2) - } 2005\end{array}$ & $A D ?$ & ALS-Parkinsonism/Dementia complex type 1 \\
\hline VEGF (Vascular Endothelial Growth Factor; 6p21.1) & AD? & ALS, Microvascular complications of diabetes 1 \\
\hline
\end{tabular}

in familial ALS, as nearly half of patients with SOD1 and FUS genes mutations become symptomatic at their fifties and $90 \%$ at their seventies ${ }^{12}$. There is also a good correlation between genetic subtypes and general age at onset (Figure 2). Genetic anticipation is exceptionally seen. There is also a tendency to progress with more prominent bulbar symptoms in familial ALS than in sporadic cases with the same age. It is important to reiterate that no specific clinical, cerebrospinal and neuroimaging parameters can rightly and reliably differentiate familial from sporadic ALS in cases without a significant familial history of neurodegeneration ${ }^{2,12,13,14}$.
There are two other clinical situations which should be remembered in the context of familial and sporadic ALS: young-onset and juvenile ALS. Young-onset ALS starts before 45 years old, corresponds to $10 \%$ of all ALS cases and tends to present less commonly with bulbar-onset symptoms. Most cases arise in the context of sporadic ALS ${ }^{15}$. Juvenile ALS represents cases starting very early before 25 years of age with slowly progressive ALS, serving as a guide and key-element for clinical suspicion of autosomal recessive familial cases ${ }^{6,15}$. Juvenile forms are frequently described in ALS2, ALS4, ALS5, ALS6 (rarely), ALS15 and ALS16 . 


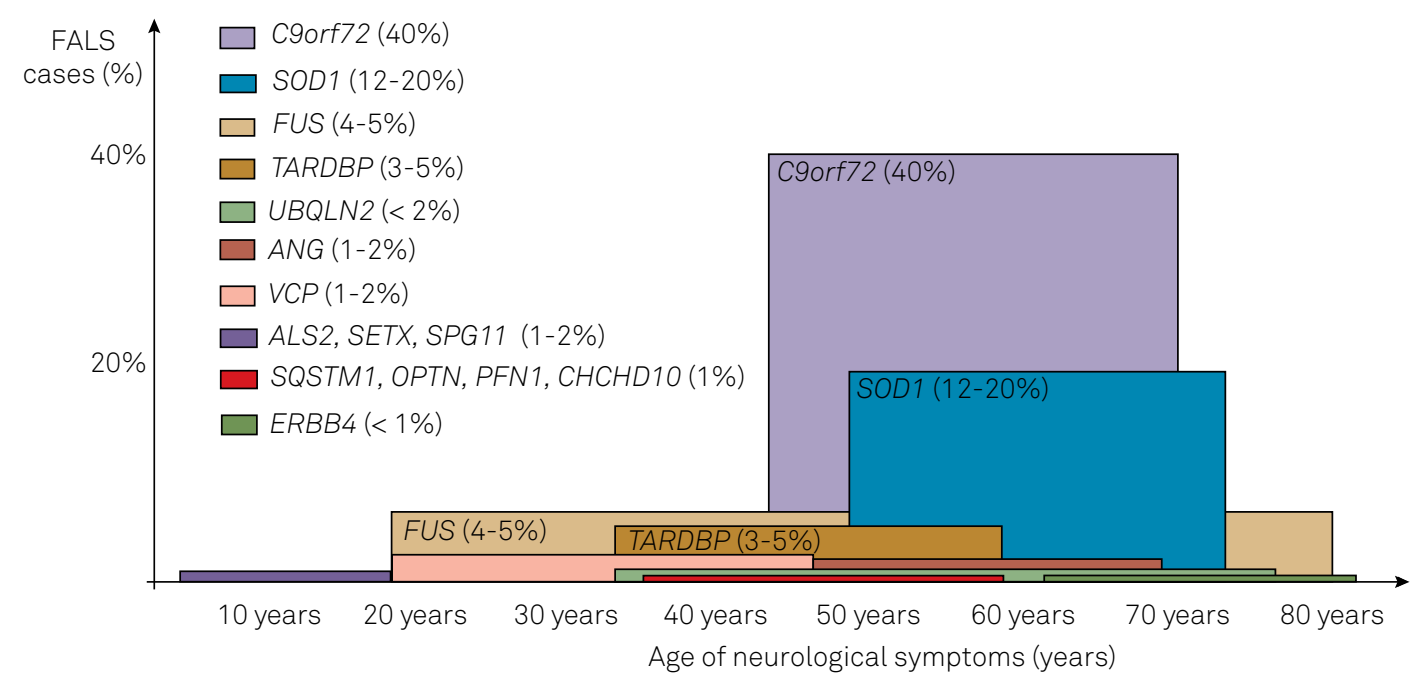

Figure 2. Distribution of the most important genetic causes of familial ALS according to the age of onset of neurological signs and symptoms. The proportion of each gene in relation to all familial cases is also represented ${ }^{4,8}$.

\section{CLINICAL AND GENETIC FORMS OF FAMILIAL ALS}

From a historical perspective, Horton classified familial forms of motor neuron disease in three main clinico-pathological phenotypes: (i) the first with early-onset motor symptoms, before five years of age, with a rapidly progressive and lower motor neuron dominant ALS phenotype, with degeneration of corticospinal tracts and anterior horn motoneurons; (ii) the second form clinically similar, but also with posterior column and spinocerebellar tract degenerations; and (iii) a third form similar to the second, but with prolonged survival period of up to two decades ${ }^{16}$.

The genetic history of familial ALS can be summed up by the outstanding roles of SOD1 and C9orf72 genes. By 2011, the year of the initial description of the hexanucleotide repeat expansion of C9orf 72 gene, only $30 \%$ of familial cases had established their genetic etiology ${ }^{5,8,17,18,19}$. In the last decade, more than 20 different loci were related to familial ALS.

Despite the marked heterogeneity of familial ALS, it can be said that most cases relate to C9orf72, SOD1, FUS, TARDBP and $U B Q L N 2$ genes $^{6,8}$. Thus, it is also possible to set specific genetic test batteries for recessive and autosomal dominant and $\mathrm{X}$-linked forms, according to inheritance patterns, clinical comorbitidities, natural history and clinical evolution, and population epidemiology. However, up to $32 \%$ of familial cases and up to $11 \%$ of sporadic cases still do not have a definite genetic diagnosis of $\mathrm{ALS}^{2,7,8,19}$.

Establishing a definite diagnosis of familial ALS is complex. In an Italian study with 53 families, genetic screening for seven of the most important genes (SODI, C9orf72, TARDBP, FUS, ANG, ATXN2, OPTN) disclosed only $25 \%$ of definite genetic diagnosis with $75 \%$ of them with two family members clinically affected and $17 \%$ with only one affected family member first and second degrees away ${ }^{14}$.
There is a lot of controversy regarding the role of most genes discovered nowadays in relation to ALS, as some of them do not have a unique causative mechanism (i.e. SOD1, C9ORF72, SETX, ANG, SPG11, FUS, TARDBP, VAPB, VCP, $U B Q L N 2, O P T N$, among others) but a disease-modifying function or susceptibility loci (i.e. PGRN, HFE, NEFH, UNC13A, $V E G F$, among others) ${ }^{4,13}$. Further discussions regarding genetic and clinical basis of familial ALS types will be provided forth (Tables 1 and 2).

\section{ALS1}

ALS1 (MIM \#105400) represents the second most common form of familial ALS, giving rise to up to $20 \%$ of cases with an autosomal dominant or recessive inheritance. SOD1 gene (superoxide dysmutase-1; 21q22.11) mutations give rise to abnormal function of copper/zinc superoxide dysmutase 1, responsible for converting superoxide free radical species from cytoplasm and inner intermembrane mitochondrial space into molecular oxygen and hydrogen peroxide. Secondary dysfunction of tyrosine phosphatases with phosphorilation inhibition by EGF (epidermal growth factor), IGF-1 (insulin-like growth factor 1) and FGF-2 (fibroblast growth factor-2) by MAPK (mitogen-activated protein kinase) pathway ${ }^{7,20}$.

By 2011,SOD1-associated ALS( formerly the 21q-associated ALS) represented the most common form of familial and sporadic ALS. Most cases present with adult-onset ALS without cognitive compromise and variable clinical outcomes depending on the genetic background involved in each case $e^{4,720}$. Rapidly progressive forms of SOD1 familial ALS occur in USA with p.Ala4Val mutation. Slowly progressive cases correlate to p.Asp90Ala mutation in Scandinavia and p.His46Arg in Japan. A LMN dominant ALS variant linked to SOD1 was described in cases of p.Ala4Val e p.Val148Gly mutations. A 
Table 2. Diagnostic cues and hallmarks of each type of familial ALS 2,8,58.

\begin{tabular}{|c|c|}
\hline ALS type (gene involved; locus) & Hallmarks \\
\hline ALS1 (SOD1; 21q22.11) & No specific clinical milestones \\
\hline ALS2 (ALS2; 2q33.1) & Juvenile (<10 years); AR; UMN-ALS, PS; facial spasticity \\
\hline ALS3 (18q21) & No specific clinical milestones \\
\hline ALS4 (SETX; 9q34.13) & Juvenile (< 20 years);AD; no bulbar/respiratory compromise; SMA-like phenotype with pyramidal signs \\
\hline ALS5 (SPG11; 15q21.1) & Juvenile (<25 years); AR; slowly progressive \\
\hline ALS6 (FUS/TLS; 16p11.2) & Wide; Rapidly progressive juvenile variant (20-30 years) \\
\hline ALS7 (20p13) & No specific clinical milestones \\
\hline ALS8 (VAPB; $20 \mathrm{q} 13.32)$ & Brazilian/Portuguese ascendancy; rapidly progressive, postural tremor, late-onset SMA, LMN-ALS \\
\hline ALS9 (ANG; 14q11.2) & Bulbar-onset, parkinsonism, late-onset FTD; LMN-ALS \\
\hline ALS10 (TARDBP; $1 \mathrm{p} 36.22)$ & No cognitive compromise; slowly progressive \\
\hline $\operatorname{ALS} 11(F / G 4 ; 6 q 21)$ & AR; prominent pyramidal signs \\
\hline ALS12 (OPTN; 10p13) & Japanese/Italian ascendancy; slowly progressive; glaucoma, Paget's disease of bone \\
\hline ALS13 (ATXN2; 12q24.12) & SCA2 and late-onset parkinsonism family history \\
\hline ALS14 (VCP; 9p13.3) & Early-onset Paget disease, FTD, inclusion body myopathy \\
\hline ALS15 (UBQLN2; Xp11.21) & XD; early bulbar symptoms; young-onset ALS, dystonia, athetosis; variable brain iron accumulation \\
\hline ALS16 (SIGMAR1; 9p13.3) & Saudi Arabia; AR; starts with spastic paraparesis; no bulbar/respiratory/cognitive signs \\
\hline ALS17 (CHMP2B; 3p11.2) & LMN-ALS; FTD \\
\hline ALS18 (PFN1;17p13.2) & No bulbar-onset symptoms; young-onset ALS \\
\hline ALS19 (ERBB4; 2q34) & Japan; late-onset, no cognitive signs \\
\hline ALS20 (HNRNPA1; 12q13.13) & Inclusion body myopathy, early-onset Paget disease; no cognitive signs \\
\hline ALS21 (MATR3; 5q31.2) & Vocal cord palsy, inclusion body myopathy; cognition \\
\hline FTD-ALS type 1 (C9orf72; 9p21.2) & Complex familial history; broader neurological phenotype \\
\hline FTD-ALS type 2 (CHCHD10; 22q11.23) & French/Spanish; FTD, parkinsonism, sensorineural deafness, ataxia, myopathy with ragged-red fibers \\
\hline $\begin{array}{l}\text { ALS-Parkinsonism/Dementia complex } \\
\text { type } 1 \text { (TRPM7; 15q21.2) }\end{array}$ & Parkinsonism; FTD; Chamorro population (Guam Island) \\
\hline TUBA4A-linked ALS (TUBA4A; 2q35) & No specific clinical milestones; FTD \\
\hline DCTN1-linked ALS (DCTN1; 2p13.1) & Perry syndrome; FTD; parkinsonism; vocal cord palsy \\
\hline NEFH-linked ALS (NEFH; 22q12.2) & Scandinavian; monomelic ALS, FTD, severe dysphagia \\
\hline EWSR1-linked ALS (EWSR1; 22q12.2) & No specific clinical milestones \\
\hline TAF15-linked ALS (TAF15; 17q12) & No specific clinical milestones \\
\hline DAO-linked ALS (DAO; 12q24.11) & No specific clinical milestones \\
\hline SMN1-linked ALS (SMN1; 5q13.2) & LMN-ALS \\
\hline PRPH-linked ALS (PRPH; 12q13.12) & No specific clinical milestones; neuroaxonal spheroids \\
\hline SQSTM1-linked ALS (SQSTM1; 5q35.3) & Paget's disease of bone \\
\hline VEGF-linked ALS (VEGF;6p21.1) & 2578AA genotype in males \\
\hline Juvenile ALS with Dementia & Dutch, Juvenile (<10 years); AR, dementia \\
\hline Utah Juvenile ALS Cluster & Utah/USA, Juvenile (<10 years); AR, UMN-ALS, ptosis, gynecomastia, hypopalesthesia \\
\hline
\end{tabular}

AR: autosomal recessive; AD: autosomal dominant; XD:X-linked dominant; ALS: Amyotrophic Lateral Sclerosis; FTD: frontotemporal dementia; UMN-ALS: upper motor neuron-dominant ALS; LMN-ALS: lower motor neuron-dominant ALS; SMA: spinal muscular atrophy; PS: pseudobulbar syndrome; SCA2: spinocerebellar ataxia type 2.

cerebellar ataxia variant with slow progression was described in Scandinavia in cases of p.Asp90Ala mutation ${ }^{7,20}$.

\section{ALS2}

ALS2 (MIM \#205100) represents a rare autosomal recessive slowly progressive UMN-dominant juvenile ALS as a consequence of homozigosity mutations in $A L S 2$ gene (2q33.1), coding alsin, involved in the membrane and endosomal intracellular trafficking as guanine nucleotide exchange factor for Rac1 and Rab5 GTPases, in neurite outgrowth in hippocampus mediated by Racl activation and in prevention of glutamartegic excitoxicity mediated by Glur2 subunit of AMPA ( $\alpha$-amino-3-hydroxy-5-methyl-4-isoxazolepropionic acid) receptors ${ }^{15,21}$. It begins in preschool child until the young adult ages (up to third decade) and has been described in japanese, turkish, tunisian, kuwaitian, saudi arabian, cypriot and Amish population. ALS2 starts with lower limb and facial spasticity, moderate muscular atrophy, pseudobulbar signs, spastic dysathrophonia and bladder dysfunction evolving statically after two decades. Important clinical overlap with allelic forms of Juvenile primary lateral sclerosis and infantile ascending hereditary spastic paralysis occurs ${ }^{13,15,21}$.

\section{ALS3}

ALS3 (MIM \%606640) represents a rare autosomal dominant adult-onset familial ALS with lower limb onset associated with 18q21 locus. Classicaly evolves to respiratory failure and death five years after onset ${ }^{22}$. 
ALS4

ALS4 (MIM \#602433) represents a rare autosomal dominant slowly progressive juvenile ALS associated with mutations in SETX gene (9q34.13), coding the protein senataxin, a DNA/RNA helicase domain involved in RNA processing and metabolism, in DNA repair mechanisms and in RNA polymerase II-dependent transcription. A toxic gain of function generally arises ${ }^{4,23}$. Very early-onset (generally before 6 years up to adolescence) with prominent distal muscular atrophy and eventually cerebellar ataxia are clues to diagnosis, mimicking spinal muscular atrophy with pyramidal signs and some forms of hereditary distal motor neuropathy. Corticospinal tract and dorsal column changes may be seen in neuroimaging. Ataxia with oculomotor apraxia type 2 is an allelic condition ${ }^{4,23}$.

\section{ALS5}

ALS5 (MIM \%602099) represents a rare autosomal recessive slowly progressive juvenile ALS, arising from missense and frameshift mutations or deletions in SPG11 gene (15q21.1), coding spatacsin, involved in axonal outgrowth and intracellular trafficking. ALS5 represents solely the most

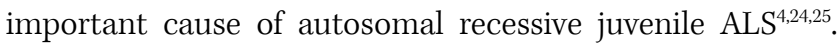
Prominent tongue fasciculations and amyotrophy in the first two decades evolve in up to three decades with upper motor neuron signs and spastic dysarthrophonia. Faster clinical courses were described in late-onset cases ${ }^{24,25}$. Allelic condition to Hereditary Spastic Paraplegia type $11^{25}$.

\section{ALS6}

ALS6 (MIM \#608030) represents an autosomal recessive or dominant adult or late-onset LMN-dominant familial ALS associated with heterozygous mutations in the FUS/TLS gene (fused in sarcoma, translated in liposarcoma; 16p11.2), coding the FUS nucleoprotein, involved with DNA repair, transcription activation, and with RNA splicing and transport to the cytoplasm. FUS associates with TDP-43 protein during the formation of SMN complex in spliceosome maintenance $e^{6,26,27}$. Up to $4 \%$ of familial and $1 \%$ of sporadic ALS arise from mutations in FUS gene, most commonly in USA, Cape Verdean and Europe (Germany, Italy, France, French-Canadian, United Kingdom). A rare juvenile variant with basophilic inclusions has also been described with a rapidly progressive motor phenotype starting during the second to third decade. Clinic and genetic correlations links p.Lys525Pro mutation with an aggressive rapidly progressive phenotype. Allelic disorders include hereditary essential tremor type 4 and FUS-related FTD ${ }^{6,26,27}$.

\section{ALS7}

ALS7 (MIM \%608031) represents a rare autosomal dominant adult-onset familial ALS, occurring in USA in association with ALS7 locus (20p13) without FTD or other systemic signs ${ }^{28}$.
ALS8

ALS8 (MIM \#608627) represents a rare autosomal dominant slowly progressive LMN-dominant familial ALS, related to heterozygous mutation in VAPB gene (vesicle-associated membrane protein-associated protein $B$, synaptobrevin-associated membrane protein B; 20q13.32), coding the VAPB protein lnked to the response supression to unfolded protein accumulation in endoplasmic reticulum and microtubule-associated membrane transport, presynaptic neuronal terminal formation and vesicular trafficking ${ }^{29}$.

A complex spectrum of neurological emerges, including: (i) a rapidly progreressive adult-onset severe $\mathrm{LMN}$-dominant ALS; (ii) atypical slowly progressive ALS with postural tremor; and (iii) late-onset spinal muscular atrophy type Finkel. Cases were described mainly in Brazilian families and portuguese and United Kingdom ascending patients ${ }^{29}$.

\section{ALS9}

ALS9 (MIM \#611895) represents a rare bulbar-onset autosomal dominant familial ALS linked to heterozygous mutation in $A N G$ gene (angiogenin; 14q11.2), coding angiogenin protein (pancreatic ribonuclease A, superfamily 5), involved with angiogenic activity in motoneurons acting as a neovascularization inducer, ribosomal RNA formation and inducing cellular proliferation by VEGF (vascular endothelial growth factor). Cases were reported in Ireland, Scotland, Italy, USA, northeastern Europe and France. $A N G$-related ALS represents near $2 \%$ of familial cases. Atypical parkinsonism with late-onset frontotemporal dementia, rapidly progressive variants and LMN-dominant ALS with parkinsonism and FTD have also been described ${ }^{4,30}$.

\section{ALS10}

ALS10 (MIM \#612069) represents a rare early-onset autosomal LMN-dominant familial ALS, linked to heterozygous missense mutations in TARDBP gene (TDP-43, transactive response DNA binding protein $43 k D a$; 1p36.22), coding the RNA-ligand TDP-43 (TAR DNA-binding protein 43-kD) ribonucleoprotein, involved in regulation of protein expression, transcription and translation, pre-mensager RNA alternative splicing and microRNA biogenesis ${ }^{6,20,31}$. ALS10 represent up to $5 \%$ of familial ALS cases and $2 \%$ of sporadic cases, being described in Italy (Sardinia), France, Germany, Japan, England, Australia and China. TARDBP-associated ALS also occur as long-standing symptoms in the upper limbs and with bulbar-onset in Asian patients. Clinical and genetical correlations are well-established: G298S mutations with rapidly progressive course, A315T and M337V mutations with longer survival periods ${ }^{6,20,31}$.

\section{ALS11}

ALS11 (MIM \#612577) represents a rare autosomal dominant adult-onset ALS or PLS, related to heterozigous missense mutations in FIG4 gene (phosphatidylinositol 3,5-bisphophate 
5-phosphatase, Sac domain-containing inositol phosphatase 3; 6q21), coding the FIG4 protein, a 5-phosphatase acting on phosphatidyl-inositol-3,5-biphosphate involved in dynamic changes in endosomal membranes during fission and fusion processes in intracellular transport from lysossomes and late endosomes to the trans-Golgi system, giving rise to authophagia dysfunction and motorneuron vacuolization in anterior horn. FIG4-related disorders include a broader spectrum including Yunis-Varon syndrome, Charcot-Marie-Tooth type 4J and bilateral temporooccipital polimicrogyria ${ }^{6,32}$.

\section{ALS12}

ALS12 (MIM \#613435) represents a rare autosomal recessive or dominant slowly progressive familial ALS sith dominant UMN signs, resulting from homozygous or heterozygous mutations in OPTN gene (optineurin; 10p13), coding optineurin protein related to nuclear factor-kappa B (NF-אB) inhibition or activation by TNF- $\alpha$ pathways, Golgi complex manteinance, autophagy induction and interacting with huntingtin, Rab8 and transcription factor IIIA ${ }^{6,33}$. Cases were described in japanese and italian families starting in the third or fifth decades with bulbar compromise at early and moderate disease stages. Allelic disorders include Paget disease of bone and primary open-angle glaucoma type $1^{4,6,33}$.

\section{ALS13}

ALS13 (MIM \#183090) represents an autosomal dominant form of familial ALS in families with spinocerebellar ataxia phenotypes, related to intermediate repeat lengths of CAG trinucleotide (27-33 repeats, generally more than 31 ) in the 5-prime end of the coding region in the exon 1 of the ATXN2 gene (ataxin 2; 12q24.12), coding ataxin-2, involved with EGF receptor trafficking as a negative regulator of endocytosis by interactions with endophilins $\mathrm{Al}$ and $\mathrm{A}$, forms a RNA-dependent complex with TDP-43, and interacts with PABP protein (poly-A-binding-protein 1) in motoneurons ${ }^{6,34}$. Cases were described in Belgium, Netherlands, France and Canada. Intermediate repeat lengths also correlated with late-onset Parkinson's disease and Progressive Supranuclear Palsy. More than 33 repeats are described in spinocerebellar ataxia type 2 (SCA2) $)^{6,34}$.

\section{ALS14}

ALS14 (MIM \#613954) forms a rare autosomal dominant form of familial ALS resulting from heterozygous mutations in VCP gene (valosin-containing protein; 9p13.3), coding the AAA+-ATPase valosin-containing protein, involved in substrate extraction in ubiquitin-proteosome systems, in Golgi complex biogenesis, in chlatrin-mediated membrane trafficking in endocytosis and Golgi complex, regulates protein degradation at the outer mitochondrial membrane, peroxysomal assembly, autophagosome maturation, and regulates cell cycle ${ }^{4,35}$. Up to $2 \%$ of familial ALS are $V C P$-related, occur in italian and north-american families and starts in the fourth to sixth decades with spine-onset ALS. Allelic disturbances include inclusion body myopathy, early-onset Paget disease, and frontotemporal dementia type 1 , and distal myopathy ${ }^{4,35}$.

\section{ALS15}

ALS15 (MIM \#300857) represents the rare dominant X-linked form of familial ALS with incomplete penetrance related to mutations in UBQLN2 gene (ubiquilin 2; Xp11.21), coding ubiquilin-2, linked to ubiquilin regulator family of ubiquitin-proteosome system and autophagy ${ }^{6,36}$. Up to $2 \%$ of familial ALS cases have a X-linked pattern of inheritance, most commonly in the first third to fifth decades, and starts with bulbar-onset disease evolving with FTD, dystonia, athetosis and spastic tetraparesis. Neuroimaging unveils cortical and basal ganglia atrophy, rarely with brain iron accumulation in basal ganglia ${ }^{6,36}$.

\section{ALS16}

ALS16 (MIM \#614373) represents an autosomal recessive UMN-dominant juvenile ALS (starting in preschool and early infancy), linked to homozygous E102Q mutations in the SIGMAR1 gene (sigma nonopioid intracellular receptor 1; 9p13.3) in Saudi Arabia, coding the S1R receptor, an endoplasmic reticulum chaperone of the cholinergic post-synaptic membrane, which binds neurosteroids, psychostimulants and involved in potassium chanell regulation and calcium signaling by IP3 receptors in cortical and spinal cord motoneurons. Ubiquitin-proteosome system abnormalities and abnormal motoneuron apoptosis have also been described ${ }^{6,37}$.

\section{ALS17}

ALS17 (MIM \#614696) represents an autosomal dominant form of lower motor neuron dominant familial ALS (sometimes associated with FTD) related to missense heterozygous mutations in the CHMP2B gene (Chromatin-modifying protein $2 B$ or charged multivesicular body protein $2 B$; $3 \mathrm{p} 11.2$ ), coding the VPS2B protein (vacuolar protein sorting 2), involved with the endosomal sorting complex ESCRT-III linked to degradation of surface receptors to the trans-Golgi and lysosomal networks, formation of multivesicular endocytic bodies, axonal transport, protein translation and MAPK intracellular pathways ${ }^{38}$.

\section{ALS18}

ALS18 (MIM \#614808) represents a rare autosomal dominant form of spinal-onset familial ALS linked to heterozygous missense mutations in the PFN1 gene (profilin 1; 17p13.2), coding the profilin-1 protein, which inhibits actin polymerization and regulates the outgrowth of the filamentous portion of (F)-actin by binding to monomeric (G)-actin. It represents up to $2 \%$ of familial cases starting in the fourth and fifth decades in caucasian and Sephardic Jewish populations without severe cognitive compromise ${ }^{2,6,39}$. 


\section{ALS19}

ALS19 (MIM \#615515) represents a rare autosomal dominant form of late-onset slowly progressive familial ALS described in japanese and canadian families, resulting from heterozygous missense mutations in $E R B B 4$ gene (V-ERB-B2 avian erythroblastic leucemia viral oncogene homolog 4; 2q34), coding the HER4 protein ligand for NDF/heregulin and neurregulin-ERBB4 pathways, involved in synaptic plasticity, cell proliferation and differentiation, glutamatergic hypofunction, and inhibition of NMDA currents and raise of AMPA currents ${ }^{40}$.

\section{ALS20}

ALS20 (MIM \#615426) represents an extremely rare autosomal dominant form of ALS with late-onset motor symptoms linked to heterozygous missense mutations in the HNRNPA1 gene (heterogeneous nuclear ribonucleoprotein Al; 12q13.13), coding the heterogeneous nuclear ribonucleoprotein A1, involved with splicing and processing of pre-messenger RNA and further metabolism and associates with core proteins of the protein moiety of the nuclear $40 \mathrm{~S}$ ribonucleoprotein particle with RNA polymerase II transcripts. Allelic disorders are represented by inclusion body myopathy with early-onset Paget's disease without frontotemporal dementia type $3^{41}$.

\section{ALS21}

ALS21 (MIM\#606070) represents a rare slowly-progressive autosomal dominant familial ALS linked to heterozygous missense mutations in the MATR3 gene (matrin3; 5q31.2), coding the matrin-3 protein, an internal matrix nuclear protein which interacts with TDP-43 participating in the aberrant processing of RNA and stabilizing messenger $\mathrm{RNA}^{42,43}$.

ALS21 (formerly the vocal cord and pharyngeal dysfunction with distal myopathy type 2) presents with adult-onset dystal myopathy with inclusion body myopathy-like features and vocal cord and pharyngeal weakness, occasionally with lower limbs brisk reflexes and tongue fasciculations and death after 15 years of symptom-onset. Other European cases were described in assocation with dementia and MND. Other Indian patient presented with adult-onset ALS and hyper-CKemia ${ }^{42,43}$.

\section{ALS22}

ALS22 (MIM \#616208), a recently described rare form of adult-onset familial ALS, correlates with TUBA4A gene (Tubulin, Alpha-4A; 2q35), coding the tubulin-alpha-4A protein, involved with microtubule network stabilization and reducing repolimerization dynamics. This form presents with late-onset familial spinal-dominant ALS with or without $\mathrm{FTD}^{44}$.

\section{FTD-ALS type 1}

FTD-ALS type 1 (MIM \#105550) represents the most common form of familial ALS. It occurs in an autosomal dominant inherited pattern in association with FTD and is associated with hexanucleotide repeat expansion (GGGGCC) in the non-conding intronic region of 5 ' regulatory region of $C 9$ orf 72 gene (chromosome 9 open reading frame 72; 9p21.2), coding the C9orf72 protein, involved in multiple intracellular mechanisms ${ }^{45,46}$.

Loss of function by happloinsufficiency and toxic gain-of-function mechanisms are both present. C9orf72-related disorders result from abnormal membrane and endosomal trafficking (related to ubiquilin-2, HNRNPA1 and HNRNPA2B1 proteins), abnormal RNA processing and metabolism (with toxic RNA foci and gain-of-function), abnormal functions of ubiquitin-proteosome system, abnormal regulation of Rab guanine-nucleotide exchange factors involved with autophagia, and secondary axonal transport disturbances. Abnormal expansion repeats form RNA G-quadruplexes with distinct structures and promote formation of DNA/RNA hybrid R-loops with linkage of aborted transcripts to the expanded regions in ribonucleoproteins leading to nucleolar stress and neuronal apoptosis. Another mechanism involves the translation of expansion transcripts without the ATG start codon, the so-called RAN process (repeat-associated non-ATG translation), generating polipeptides with poli-glycine-arginine and poli-proline-arginine (also called dipeptide repeat proteins), which leads to neutoxicity by direct effects to DNA and binding to HNRNPA2 and changing RNA biogenesis ${ }^{8,46,47,48,49}$.

Some neuropathological and molecular signatures from C9orf72-related disorders differentiate them from other ALS and FTD genetic forms. Spinal motor neurons and glial cells may present with TDP-43 positive cytoplasmic inclusions in association with cortical and spinal cord intraneuronal cytoplasmic ubiquitin-positive, Tau-negative inclusions, FUS-negative and Ubiquilin 2 positive inclusions ${ }^{12}$. The same way, a nearly pathognomonic neuromolecular marker of C9orf72-related disorder is the presence of TDP-43 negative and p62-positive intraneuronal intracytoplasmic inclusions with dipeptide repeat proteins in extraspinal regions (dentate gyrus granule cells in the CA4 pyramidal cells of the hippocampus, frontal neocortex, and granule cells of the cerebellum). These dipeptide repeat proteins result from sense and antisense repeat associated non ATG-initiated translation of the expanded repeat noncoding region, previously described. Furthermore, the loss of dopaminergic neurons in substantia nigra has also been described in C9orf72-related ALS with parkinsonism, p62-positive inclusions and $\alpha$-synuclein-negative Lewy bodies ${ }^{12}$.

C9orf72-associated ALS represents the main discovery in neuromuscular genetics since 2011 (former chromosome 9p-linked FTD with ALS) ${ }^{48,49}$ and the major cause of ALS ranging from one third up to $46 \%$ of familial cases and from $6 \%$ up to $21 \%$ of sporadic cases ${ }^{20}$. There is a clear tendency of low prevalence in cases from Asian countries and Pacific islands. On the other hand, high sporadic prevalences are 
detected in Finland (with a founder effect), Sweden, United Kingdom, Netherlands, Greece and USA, and high familial rates in Belgium, Sweden, Greece, Finland, Ireland, France and United Kingdom ${ }^{46,47}$.

Neurological symptomatic cases arise with 250 up to 1600 expansion repeats, as healthy people most commonly present with 2 to 19 repeats $^{46,47}$. The clinical picture of $C 9$ orf72-related disorders is expanding its phenotypical spectrum. Family history of FTD-ALS patients may unveil dementia (with FTD, dementia with diffuse Lewy bodies or Alzheimer's disease), atypical parkinsonism (with rapidly progressive progressive supranuclear palsy and corticobasal degeneration), complex movement disorders (Huntington's disease-like), and psychiatric disorders (mainly late-onset psychosis). Intense intrafamilial clinical variability makes difficult the recognition of this neurodegenerative complex ${ }^{46,47}$.

Thus, C9orf72-related ALS must be investigated in cases of adult-onset familial ALS, mainly in non-Asian patient cases with FTD phenotype, or in cases with a complex familial network of neurodegenerative disorders, including adult and late-onset chorea, atypical parkinsonism or isolated psychiatric syndromes.

\section{FTD-ALS type 2}

FTD-ALS type 2 (MIM \#615911) represents a rare autosomal dominant form of familial ALS with frontotemporal dementia, resulting from heterozygous mutations in the CHCHD10 gene (Coiled-coil-helix-coiled-coil-helix domain-containing protein 10; 22q11.23), coding the CHCHD10 protein, involved in oxidative phosphorylation and maintenance of cristae morphology in the inner intermembranous mitochondrial space. In France and Spain patients around the fifth decade of life present with complex neurological phenotypes involving frontotemporal dementia, cerebellar ataxia, myopathy with ragged-red fibers and COX-negative fibers, motor neuron disease with progressive bulbar dysfunction, and rarely with akinetic-rigid parkinsonism and sensorineural deafness ${ }^{50}$.

\section{UNCLASSIFIED FORMS OF FAMILIAL ALS}

Several genetic forms of familial ALS, well-recognized by specialists, are not characterized as a single familial ALS form in the Monogenic Muscle Gene Table classification (World Muscle Society) ${ }^{51}$. The most distinguished forms are discussed here.

Familial forms associated to NEFH gene (neurofilament, heavy polypepeptide; 22q12.2) are involved in monomelic ALS with dementia and severe dysphagia in Scandinavia. NEFH gene codes the heavy polypeptide neurofilament, the most important neuron-specific intermediate filament of cytoskeleton in myelinated axons, involved in maintenance of cytoskeleton and axonal architecture in proximal axonal region of spinal motoneurons ${ }^{51,52}$.
PRPH-associated familial ALS represents an adult-onset ALS with Lewy body-like inclusions and neuroaxonal spheroids in proximal axonal region of spinal motoneurons. It is associated with mutations in PRPH gene (peripherin; 12q13.12), coding peripherin, an intermediate filament type 3 neuronal cytoskeleton similar to neurofilament ${ }^{51,53}$.

DCTN1-related disorders are involved in a complex spectrum of neurodegenerative allelic disorders, including hereditary distal motor neuropathy type VIIB, FTD-like phenotypes and atypical parkinsonism, like PSP and Perry syndrome. A lower motor neuron dominant slowly progressive ALS with vocal cord and facial palsy arises as a consequence of G59S heterozygous mutation in DCTN1 (dynactin 1; 2p13.1), coding dynactin-1, involved with dynactin complex connection with microtubules and cytoplasm dynein for axonal transport ${ }^{54}$.

DAO (D-aminoacid oxidase; 12q24.11) gene mutations are also involved with very rare adult-onset familial ALS. Dysfunction of D-aminoacid oxidase gives rise to abnormal downregulation of D-serine, a normal co-agonist of excitatory NMDA glutamate receptors, as a consequence of abnormal cerebellar and spinal oxidative deamination of D-aminoacids. There is association with schizophrenia in canadian patients ${ }^{6,55}$.

SQSTM1-associated ALS correlates with adult-onset autosomal dominant familial ALS associated with Paget disease of bone, representing up to $1 \%$ of familial cases. SQSTM1 gene (Sequestosome 1; 5q35.3) mutations are involved with abnormal coding of p62 protein, involved in ubiquitination and authophagy by activation of NF- $\mathrm{KB}$ pathway ${ }^{4,6}$.

TAF15 (TATA Box-binding protein-associated factor RNA polymerase II; 17q12) and EWSR1 (Ewing sarcoma breakpoint region 1; 22q12.2) genes are involved with extremely rare adult-onset familial ALS, both participating directly in transcription processes with other activators or repressors: the former coding RBP56 protein (RNA-binding protein 56), allelic to extraskeletal mixoid condrosarcoma; and the last coding EWS protein, allelic to neuroepithelioma and Ewing sarcoma ${ }^{4,6}$.

A rare autosomal recessive juvenile ALS form (MIM \%20 5200) has been described in Dutch and Amish patients with early juvenile-onset dementia during the first decade with distal muscular atrophy and death after up to two decades of symptom-onset ${ }^{56}$.

Another recently described familial ALS form has been described in Utah, USA, involving autosomal recessive inheritance and clinically manifest with upper motor neuron dominant juvenile ALS, with slowly progressive motor symptoms starting in the lower limbs and bulbar region in the first decade of life and evolving with partial eyelid ptosis, gynecomastia and mild distal hypopalesthesia ${ }^{2,3}$.

Amyotrophic lateral sclerosis-parkinsonism/dementia complex type 1 results from mutations in the TRPM7 gene (Transient receptor potential cation channel, 
subfamily $M$, member 7; 15q21.2), coding the transient receptor potential cation channel subfamily $\mathrm{M}$ member 7 , involved in regulation of oxidative stress metabolism and in the phosphorylation of different intracellular substrates. Susceptibility from direct exposure to neurotoxic effects $\beta$-methylamino-L-alanine found in local Guam species of flying fox (Pteropus tokudae) was described in patients from the Chamorro population from Guam Island in USA which posteriorly become called the Lytico-bodig disease ${ }^{57}$. Most authors do not include Lytico-bodig disease as familial ALS. However, this apparently narrowed distribution of this ALS form has also been linked to another form of ALS described in the Kii Peninsula of Japan, also known as Muro disease with a complex neurological phenotype with dementia and movement disorders (including parkinsonism, dystonia and myoclonus), in which TRPM7, C9orf72 and SOD1-related mechanisms have been described ${ }^{58}$.

\section{FAMILIAL AND SPORADIC FORMS ASSOCIATED WITH OTHER SUSCEPTIBILITY LOCI}

In many of the so-called sporadic cases, there is an important role of genetic factors usually associated with incomplete penetrance and the complex stochastic predisposing events and the individual and environmental risk factors ${ }^{59}$. Much data on susceptibility loci results from linkage analysis studies, candidate-gene association studies, genome-wide association studies and methylation analysis, copy number variants and chromosomal rearrangements studies, and whole-exome or genome-sequencing studies ${ }^{2,3,59}$. Most clinical descriptions are related to single nucleotide polymorphisms (SNPs), polyglutamine repeats, missense mutations, abnormal copy number of genes, gene promoter SNPs, and insertions and deletions ${ }^{7}$. More than 20 different gene loci have been described so far.

CYP27A1 gene (Cytochrome P450, Subfamily XXVIIA, Polypeptide 1; 2q35) mutations have been described in cerebrotendinous xanthomatosis (CTX) (MIM \#213700) and as a susceptibility loci for sporadic ALS $^{60}$. In our experience, CTX may present with an early-onset lower motor dominant juvenile ALS phenotype in two Brazilian sisters with severe bulbar compromise, orofacial dyskinesia and generalized epilepsy. One of them presented also with typical systemic signs of CTX, including chronic diarrhea, juvenile bilateral cataracts and early-onset premenopausal osteopenia (unpublished data). Other gene loci are also involved with sporadic forms described as susceptibility loci (most as SNP associations or demonstrated by genome-wide association studies) for which there is some degree of suspicion related to familial cases (Table 3$)^{2,4,7,12,13,59}$.

Table 3. Summary of the main gene loci involved with sporadic forms and with high suspicion of involvement in familial cases 2,4,7,12,13,59.

Gene involved and locus
APEX1 gene (apurinic endonuclease 1, multifunctional DNA repair enzyme;
SS18-like gene 1 (Calcium-responsive Transactivator; 20q13.33)
CAMK1G gene (Calcium/Calmodulin-dependent Protein Kinase I-Gamma;
ARHGEF28 gene (Rho Guanine Nucleotide Exchange Factor 28; 5q13.2)
HFE gene (hemochromatosis; 6 p22.2)
VEGF gene (Vascular Endothelial Growth Factor A; 6p21.1)
ITPR2 gene (inositol 1,4,5-triphosphate receptor type 2;12p12.1-p11.2)
DPP6 gene (dipeptidyl-peptidase VI; 7q36.2)
KIFAP3 gene (kinesin-associated protein 3; 1q24.2)
PLCD1 gene (Phospholipase C, Delta-1; 3p22.2)
Telomeric SMN1 gene (survival of motor neuron 1; 5q13.2) duplications
Centromeric SMN2 gene (survival of motor neuron 2; q13.2) deletions
COX1 (Complex IV, Cytochrome c Oxidase subunit I, MT-C01) gene

IARS2 (mitochondrial Isoleucyl-tRNA synthetase; 1q41) gene

PON1 gene (paraoxonase, arylesterase A; 7q21.3)

\section{Distribution and allelic disorders}

Ireland and Scotland; no allelic disorders

No allelic disorders

No allelic disorders

No allelic disorders

USA, Ireland, United Kingdom, Italy, China and Netherlands; hemochromatosis; susceptibility to porphyria variegata and cutanea tarda

Sweden, Belgium, Germany and England

No allelic disorders

No allelic disorders

No allelic disorders

Nonsyndromic congenital nail disorders (leukonychia) type 3

Spinal muscular atrophy types 1-4

Spinal muscular atrophy type 3

Leber optic atrophy, Acquired idiopathic sideroblastic anemia, cytochrome c oxidase deficiency, recurrent myoglobinuria, colorectal cancer

Cataracts, growth hormone deficiency, sensory neuropathy, sensorineural hearing loss, and skeletal dysplasia

Alzheimer's disease, idiopathic Parkinson's disease; sensitivity to organophosphate; susceptibility to coronary artery disease

Other gene loci: FGGY (FLJ10986) gene; 7p13.3 locus; SPG17/BSCL2 gene (11q13); SPG39/PNPLA6 gene (Patatin-like phospholipase domain-containing protein 6;19p13.2); UNC13A gene (KIAA1031;19p13.11);PGRN gene (granulin precursor;17q21.31); ELP3 gene (Elongator Acetyltransferase Complex, Subunit 3; 8p21.1); SUSD2 gene (Sushi Domain-Containing Protein 2; 22q11.23); EPHA4 gene (Ephrin receptor EphA4); CHGB gene (chromogranin B, secretogranin I; 20 12.3), C19orf12 gene (Mitocondrial Membrane Protein Associated Neurodegeneration-MPAN/NBIA4;19q12); GLE1 gene (GLE1, S. cerevisae, Homolog-like; 9q34.11) 


\section{CONCLUSION}

Although most cases of ALS are sporadic, familial ALS cases represent important clinical, genetic and neuropathological keys to understand the natural history of different genetic forms, clinical and genetic correlations, and allow new genetic targeted therapies for ALS. Despite the current trend of ALS diagnoses are limited to syndromic clinical descriptions, in the near future it will be essential to establish the genetic types associated with the different clinical subtypes and presentations, especially in familial cases and in complex neurological phenotypes.

\section{References}

1. Oliveira ASB, Pereira RDB. Amyotrophic lateral sclerosis (ALS): three letters that change the people's life. For ever. Arq Neuropsiquiatr. 2009;67(3A):750-82. doi:10.1590/S0004-282X2009000400040

2. Leblond CS, Kaneb HM, Dion PA, Rouleau GA. Dissection of genetic factors associated with amyotrophic lateral sclerosis. Exp Neurol. 2014;262(Part B):91-101. doi:10.1016/j.expneurol.2014.04.013

3. He J, Mangelsdorf M, Fan D, Bartlett P, Brown MA. Amyotrophic Lateral Sclerosis genetic studies: from genome-wide association mapping to genome sequencing. Neuroscientist. 2014;pii:1073858414555404. Forthcoming. doi:10.1177/1073858414555404

4. Su XW, Broach JR, Connor JR, Gerhard GS, Simmons Z. Genetic heterogeneity of amyotrophic lateral sclerosis: implications for clinical practice and research. Muscle Nerve. 2014;49(6):786-803. doi:10.1002/mus.24198

5. Ferraiuolo L, Kirby J, Grierson AJ, Sendtner M, Shaw PJ. Molecular pathways of motor neuron injury in amyotrophic lateral sclerosis. Nat Rev Neurol. 2011;7(11):616-30. doi:10.1038/nrneurol.2011.152

6. Iguchi Y, Katsuno M, Ikenaka K, Ishigaki S, Sobue G. Amyotrophic lateral sclerosis: an update on recent genetic insights. J Neurol. 2013;260(11):2917-27. doi:10.1007/s00415-013-7112-y

7. Chen S, Sayana P, Zhang X, Le W. Genetics of amyotrophic lateral sclerosis: an update. Mol Neurodegener. 2013;8(1):28. doi:10.1186/1750-1326-8-28

8. Renton AE, Chiò A, Traynor BJ. State of play in amyotrophic lateral sclerosis genetics. Nat Neurosci. 2014;17(1):17-23. doi:10.1038/nn.3584

9. Turner MR, Swash M. The expanding syndrome of amyotrophic lateral sclerosis: a clinical and molecular odyssey. $J$ Neurol Neurosurg Psychiatry. 2015;86(6):667-73. doi:10.1136/jnnp-2014-308946

10. Kanouchi T, Ohkubo T, Yokota T. Can regional spreading of amyotrophic lateral sclerosis motor symptoms be explained by prion-like propagation? J Neurol Neurosurg Psychiatry. 2012;83(7):739-45. doi:10.1136/jnnp-2011-301826

11. Strong MJ, Grace GM, Freedman M, Lomen-Hoerth C, Woolley $\mathrm{S}$, Goldstein LH et al. Consensus criteria for the diagnosis of frontotemporal cognitive and behavioural syndromes in amyotrophic lateral sclerosis. Amyotroph Lateral Scler 2009;10(3):131-46. doi:10.1080/17482960802654364

12. Al-Chalabi A, Jones A, Troakes C, King A, Al-Sarraj S, Berg LH. The genetics and neuropathology of amyotrophic lateral sclerosis. Acta Neuropathol. 2012;124(3):339-52. doi:10.1007/s00401-012-1022-4

13. Ticozzi N, Tiloca C, Morelli C, Colombrita C, Poletti B, Doretti A et al. Genetics of familial Amyotrophic lateral sclerosis. Arch Ital Biol. 2011;149(1):65-82. doi:10.4449/aib.v149i1.1262

14. Conte A, Lattante S, Luigetti M, Del Grande A, Romano A, Marcaccio A et al. Classification of familial amyotrophic lateral sclerosis by family history: effects on frequency of genes mutation. J Neurol Neurosurg Psychiatry. 2012;83(12):1201-3. doi:10.1136/jnnp-2012-302897

15. Turner MR, Barnwell J, Al-Chalabi A, Eisen A. Young-onset amyotrophic lateral sclerosis: historical and other observations. Brain. 2012;135(9):2883-91. doi:10.1093/brain/aws144
16. Horton WA, Eldridge R, Brody JA. Familial motor neuron disease: evidence for at least three different types. Neurology. 1976;26(5):460-5. doi:10.1212/WNL.26.5.460

17. Al-Chalabi A, Hardiman O. The epidemiology of ALS: a conspiracy of genes, environment and time. Nat Rev Neurol. 2013;9(11):617-8. doi:10.1038/nrneurol.2013.203

18. Van Langenhove T, Zee J, Van Broeckhoven C. The molecular basis of the frontotemporal lobar degeneration-amyotrophic lateral sclerosis spectrum. Ann Med. 2012;44(8):817-28. doi:10.3109/07853890.2012.665471

19. Blitterswijk M, v Es MA, Hennekam EA, Dooijes D, Rheenen W, Medic $J$ et al. Evidence for an oligogenic basis of amyotrophic lateral sclerosis. Hum Mol Genet. 2012;21(17):3776-84. doi:10.1093/hmg/dds199

20. Ince PG, Highley JR, Kirby J, Wharton SB, Takahashi H, Strong MJ et al. Molecular pathology and genetic advances in amyotrophic lateral sclerosis: an emerging molecular pathway and the significance of glial pathology. Acta Neuropathol. 2011;122(6):657-71. doi:10.1007/s00401-011-0913-0

21. Shirakawa K, Suzuki H, Ito M, Kono S, Uchiyama T, Ohashi T et al. Novel compound heterozygous ALS2 mutations cause juvenile amyotrophic lateral sclerosis in Japan. Neurology. 2009;73(24):2124-6. doi:10.1212/WNL.0b013e3181c67be0

22. Hand CK, Khoris J, Salachas F, Gros-Louis F, Lopes AA, Mayeux-Portas $V$ et al. A novel locus for familial amyotrophic lateral sclerosis, on chromosome 18q. Am J Hum Genet. 2002;70(1):251-6. doi:10.1086/337945

23. Chen YZ, Bennett CL, Huynh HM, Blair IP, Puls I, Irobi J et al. DNA/RNA helicase gene mutations in a form of juvenile amyotrophic lateral sclerosis (ALS4). Am J Hum Genet. 2004;74(6):1128-35. doi:10.1086/421054

24. Hentati A, Ouahchi K, Pericak-Vance MA, Nijhawan D, Ahmad A, Yang $Y$ et al. Linkage of a commoner form of recessive amyotrophic lateral sclerosis to chromosome 15q15-q22 markers. Neurogenetics 1998;2(1):55-60. doi:10.1007/s100480050052

25. Daoud H, Zhou S, Noreau A, Sabbagh M, Belzil V, Dionne-Laporte A et al. Exome sequencing reveals SPG11 mutations causing juvenile ALS. Neurobiol Aging. 2012;33(4):839:e5-9. doi:10.1016/j.neurobiolaging.2011.11.012

26. Hewitt C, Kirby J, Highley JR, Hartley JA, Hibberd R, Hollinger HC et al. Novel FUS/TLS mutations and pathology in familial and sporadic amyotrophic lateral sclerosis. Arch Neurol. 2010;67(4):455-61. doi:10.1001/archneurol.2010.52

27. Bäumer D, Hilton D, Paine SM, Turner MR, Lowe J, Talbot $\mathrm{K}$ et al. Juvenile ALS with basophilic inclusions is a FUS proteinopathy with FUS mutations. Neurology. 2010;75(7):611-8. doi:10.1212/WNL.0b013e3181ed9cde

28. Sapp PC, Hosler BA, McKenna-Yasek D, Chin W, Gann A, Genise $\mathrm{H}$ et al. Identification of two novel loci for dominantly inherited familial amyotrophic lateral sclerosis. Am J Hum Genet. 2003;73(2):397-403. doi:10.1086/377158

29. Nishimura AL, Mitne-Neto M, Silva HCA, Richieri-Costa A, Middleton $S$, Cascio $D$ et al. A mutation in the vesicle-trafficking protein VAPB causes late-onset spinal muscular atrophy and amyotrophic lateral sclerosis. Am J Hum Genet. 2004;75(5):822-31. doi:10.1086/425287 
30. Millecamps S, Salachas F, Cazeneuve C, Gordon P, Bricka B, Camuzat A et al. SOD1, ANG, VAPB, TARDBP, and FUS mutations in familial amyotrophic lateral sclerosis: genotype-phenotype correlations. J Med Genet. 2010;47(8):554-60. doi:10.1136/jmg.2010.077180

31. Corcia P, Valdmanis P, Millecamps S, Lionnet C, Blasco H, Mouzat $K$ et al. Phenotype and genotype analysis in amyotrophic lateral sclerosis with TARDBP gene mutations. Neurology. 2012;78(19):1519-26. doi:10.1212/WNL.0b013e3182553c88

32. Chow CY, Landers JE, Bergren SK, Sapp PC, Grant AE, Jones JM et al. Deleterious variants of FIG4, a phosphoinositide phosphatase, in patients with ALS. Am J Hum Genet. 2009;84(1):85-8. doi:10.1016/j.ajhg.2008.12.010

33. Maruyama H, Morino H, Ito H, Izumi Y, Kato H, Watanabe $Y$ et al. Mutations of optineurin in amyotrophic lateral sclerosis. Nature. 2010;465(7295):223-6. doi:10.1038/nature08971

34. Van Damme P, Veldink JH, Blitterswijk M, Corveleyn A, Vught PW, Thijs $\checkmark$ et al. Expanded ATXN2 CAG repeat size in ALS identifies genetic overlap between ALS and SCA2. Neurology. 2011;76(24):2066-72. doi:10.1212/WNL.0b013e31821f445b

35. Johnson JO, Mandrioli J, Benatar M, Abramzon Y, Van Deerlin VM, Trojanowski JQ et al. Exome sequencing reveals VCP mutations as a cause of familial ALS. Neuron. 2010;68(5):857-64. doi:10.1016/j.neuron.2010.11.036

36. Deng HX, Chen W, Hong ST, Boycott KM, Gorrie GH, Siddique N et al. Mutations in UBQLN2 cause dominant X-linked juvenile and adult-onset ALS and ALS/dementia. Nature. 2011;477(7363):211-5. doi:10.1038/nature10353

37. Al-Saif A, Al-Mohanna F, Bohlega S. A mutation in sigma-1 receptor causes juvenile amyotrophic lateral sclerosis. Ann Neurol. 2011;70(6):913-9. doi:10.1002/ana.22534

38. Cox LE, Ferraiuolo L, Goodall EF, Heath PR, Higginbottom A, Mortiboys $\mathrm{H}$ et al. Mutations in CHMP2B in lower motor neuron predominant amyotrophic lateral sclerosis (ALS). PLoS One. 2010;5(3):e9872. doi:10.1371/journal.pone.0009872

39. Wu CH, Fallini C, Ticozzi N, Keagle PJ, Sapp PC, Piotrowska Ket al. Mutations in the profilin 1 gene cause familial amyotrophic lateral sclerosis. Nature 2012;488(7412):499-503. doi:10.1038/nature11280

40. Takahashi Y, Fukuda Y, Yoshimura J, Toyoda A, Kurppa K, Moritoyo $\mathrm{H}$ et al. ERBB4 mutations that disrupt the neuregulin-ErbB4 pathway cause amyotrophic lateral sclerosis type 19. Am J Hum Genet. 2013;93(5):900-5. doi:10.1016/j.ajhg.2013.09.008

41. Kim HJ, Kim NC, Wang YD, Scarborough EA, Moore J, Diaz Z et al. Mutations in prion-like domains in hnRNPA2B1 and hnRNPA1 cause multisystem proteinopathy and ALS. Nature. 2013;495(7442):467-73. doi:10.1038/nature11922

42. Feit H, Silbergleit A, Schneider LB, Gutierrez JA, Fitoussi RP, Réyès C et al. Vocal cord and pharyngeal weakness with autosomal dominant distal myopathy: clinical description and gene localization to 5q31. Am J Hum Genet. 1998;63(6):1732-42. doi:10.1086/302166

43. Johnson JO, Pioro EP, Boehringer A, Chia R, Feit H, Renton AE et al. Mutations in the Matrin 3 gene cause familial amyotrophic lateral sclerosis. Nat Neurosci. 2014;17(5):664-6. doi:10.1038/nn.3688

44. Smith BN, Ticozzi N, Fallini C, Gkazi AS, Topp S, Kenna KP et al. Exome-wide rare variant analysis identifies TUBA4A mutations associated with familial ALS. Neuron. 2014;84(2):324-31. doi:10.1016/j.neuron.2014.09.027

45. Souza PV, Pinto WB, Oliveira AS. C9orf72-related disorders: expanding the clinical and genetic spectrum of neurodegenerative diseases. Arq Neuropsiquiatr. 2015;73(3):246-56. doi: 10.1590/0004-282X20140229

46. Woollacott IO, Mead S. The C9ORF72 expansion mutation: gene structure, phenotypic and diagnostic issues. Acta Neuropathol. 2014;127(3):319-32. doi:10.1007/s00401-014-1253-7

47. Cooper-Knock J, Shaw PJ, Kirby J. The widening spectrum of C9ORF72-related disease; genotype/phenotype correlations and potential modifiers of clinical phenotype. Acta Neuropathol. 2014;127(3):333-45. doi:10.1007/s00401-014-1251-9

48. Renton AE, Majounie E, Waite A, Simón-Sánchez J, Rollinson S, Gibbs JR et al. A hexanucleotide repeat expansion in C90RF72 is the cause of chromosome 9p21-linked ALS-FTD. Neuron. 2011;72(2):257-68. doi:10.1016/j.neuron.2011.09

49. DeJesus-Hernandez M, Mackenzie IR, Boeve BF, Boxer AL, Baker M, Rutherford NJ et al. Expanded GGGGCC hexanucleotide repeat in noncoding region of C9ORF72 causes chromosome $9 p$-linked FTD and ALS. Neuron. 2011;72(2):245-56. doi:10.1016/j.neuron.2011.09.011

50. Bannwarth S, Ait-El-Mkadem S, Chaussenot A, et al. A mitochondrial origin for frontotemporal dementia and amyotrophic lateral sclerosis through CHCHD10 involvement. Brain. 2014;137(8):2329-45. doi:10.1093/brain/awu138

51. Kaplan JC, Hamroun D. The 2015 version of the gene table of monogenic neuromuscular disorders (nuclear genome). Neuromuscul Disord. 2014;24(12):1123-53. doi:10.1016/j.nmd.2014.11.001

52. Al-Chalabi A, Andersen PM, Nilsson P, Chioza B, Andersson JL, Russ $C$ et al. Deletions of the heavy neurofilament subunit tail in amyotrophic lateral sclerosis. Hum Molec Genet. 1999;8(2):157-64. doi:10.1093/hmg/8.2.157

53. Leung CL, He CZ, Kaufmann P, Chin SS, Naini A, Liem RK et al. A pathogenic peripherin gene mutation in a patient with amyotrophic lateral sclerosis. Brain Path. 2004;14(3):290-6. doi:10.1111/j.1750-3639.2004.tb00066.x

54. LaMonte BH, Wallace KE, Holloway BA, Shelly SS, Ascaño J, Tokito $M$ et al. Disruption of dynein/dynactin inhibits axonal transport in motor neurons causing late-onset progressive degeneration. Neuron. 2002;34(5):715-27. doi:10.1016/S0896-6273(02)00696-7

55. Millecamps S, Da Barroca S, Cazeneuve C, Salachas F, Pradat PF, Danel-Brunaud $V$ et al. Questioning of the role of D amino acid oxidase in familial amyotrophic lateral sclerosis. Proc Natl Acad Sci U SA. 2010;107(26):E107. doi:10.1073/pnas.1006190107

56. Staal A, Went LN. Juvenile amyotrophic lateral sclerosis-dementia complex in a Dutch family. Neurology. 1968;18(8):800-6. doi:10.1212/WNL.18.8.800

57. Morris HR, Al-Sarraj S, Schwab C, Gwinn-Hardy K, Perez-Tur $J$, Wood NW et al. A clinical and pathological study of motor neurone disease on Guam. Brain. 2001;124(11):2215-22. doi:10.1093/brain/124.11.2215

58. Shindo A, Ueda Y, Kuzuhara S, Kokubo Y. Neuropsychological study of amyotrophic lateral sclerosis and parkinsonism-dementia complex in Kii peninsula, Japan. BMC Neurol. 2014;14(1):151. doi:10.1186/1471-2377-14-151

59. Marangi G, Traynor BJ. Genetic causes of amyotrophic lateral sclerosis: new genetic analysis methodologies entailing new opportunities and challenges. Brain Res. 2014;1607:75-93. doi:10.1016/j.brainres.2014.10.009

60. Diekstra FP, Saris CG, van Rheenen W, Franke L, Jansen RC, Es MA et al. Mapping of gene expression reveals CYP27A1 as a susceptibility gene for sporadic ALS. PLoS One. 2012;7(4):e35333. doi:10.1371/journal.pone.0035333 